\title{
Knoop hardness anisotropy in anthracene and phenanthrene single crystals
}

\author{
NIMISHA VAIDYA, M J JOSHI, B S SHAH* and D R JOSHI ${ }^{\dagger}$ \\ Solid State Physics and Materials Science Laboratories, Department of Physics, \\ Saurashtra University, Rajkot 360005 , India \\ †Applied Physics Department, Faculty of Technology and Engineering, M. S. University of \\ Baroda, Vadodara 390002, India \\ MS received 17 April 1997; revised 6 August 1997
}

\begin{abstract}
Microhardness anisotropy in single crystals of anthracene and phenanthrene has been observed by the Knoop indentation technique. The Knoop hardness variation with respect to the $[010]$ direction shows opposite trends. Both these crystals have the same crystal structure and space group. The present observations are explained in terms of orientation and disposition of molecules in the unit cells.
\end{abstract}

Keywords. Knoop indentation: microhardness: anisotropy; anthracene; phenanthrene.

\section{Introduction}

The hardness of crystals is an important strength property. The Knoop microhardness anisotropy of aroganite has been studied (Han et al 1991). The microhardness anisotropy in calcite, dolamite and magnesite has been reported (Wong and Bradt 1992). The Knoop hardness anisotropy on (001) basal plane of $\mathrm{YBa}_{2} \mathrm{Cu}_{3} \mathrm{O}_{7-\delta}$ single crystals has been studied (Fang et al 1993). The microhardness anisotropy in some cubic crystals with different point groups have been studied (Thirmal Rao et al 1991). In organic molecular crystals, the variation in Knoop hardness number with crystal orientation on (101) habit face of PETN and on (210) habit face of RDX were reported (Miller 1989). The microhardness behaviour of benzoic acid single crystals using the Knoop indenter has been studied (Vaidya et al 1996; Vaidya and Shah 1997).

The present communication is a systematic study of the Knoop microhardness with orientation on single crystal cleavages of anthracene and phenanthrene.

\section{Experimental and results}

\subsection{Crystal growth}

Single crystals of anthracene and phenanthrene were grown from the melt by the Bridgman method. The starting material was column chromatographed, twice vacuum sublimed and zone refined. The material was transferred to the crystal growth tubes without exposure to the atmosphere (Sherwood 1969). The crystals were cleaved in the usual manner using a sharp blade. Smooth (001) cleavages were selected after optical examination.

*Author for correspondence 


\subsection{Microhardness}

The crystals were indented on a Carl Zeiss NU 2 Universal Research Microscope. The indents were made with a Knoop indenter. The loads used for phenanthrene and anthracene crystals were $7.5 \mathrm{~g}$ and $10 \mathrm{~g}$ respectively. A number of indents were made at this load. The long diagonal length was used in calculating the Knoop hardness number $\left(H_{\mathrm{k}}\right)$ using the formula:

$$
H_{\mathrm{k}}=14228.8 \times P / d^{2},
$$

where $P$ is the applied load in $g$ and $d$ the mean diagonal length in micrometers. The indentation time of $10 \mathrm{~s}$ and $30 \mathrm{~s}$ was kept constant for phenanthrene and anthracene crystals, respectively as these times were adequate to minimize the vibration effects on the results. The crystal size was much larger than the indentation size, thus eliminating the boundary effects on the results. The distance between the indents was five times the size of the largest indentation mark. The crystal thickness was relatively large such that the indenter did not sense the lower surface (Mott 1956). A number of crystals were indented.

Figures 1 and 2 show variation of the Knoop hardness with orientation for crystals of anthracene and phenanthrene. It is observed that the hardness is maximum when the

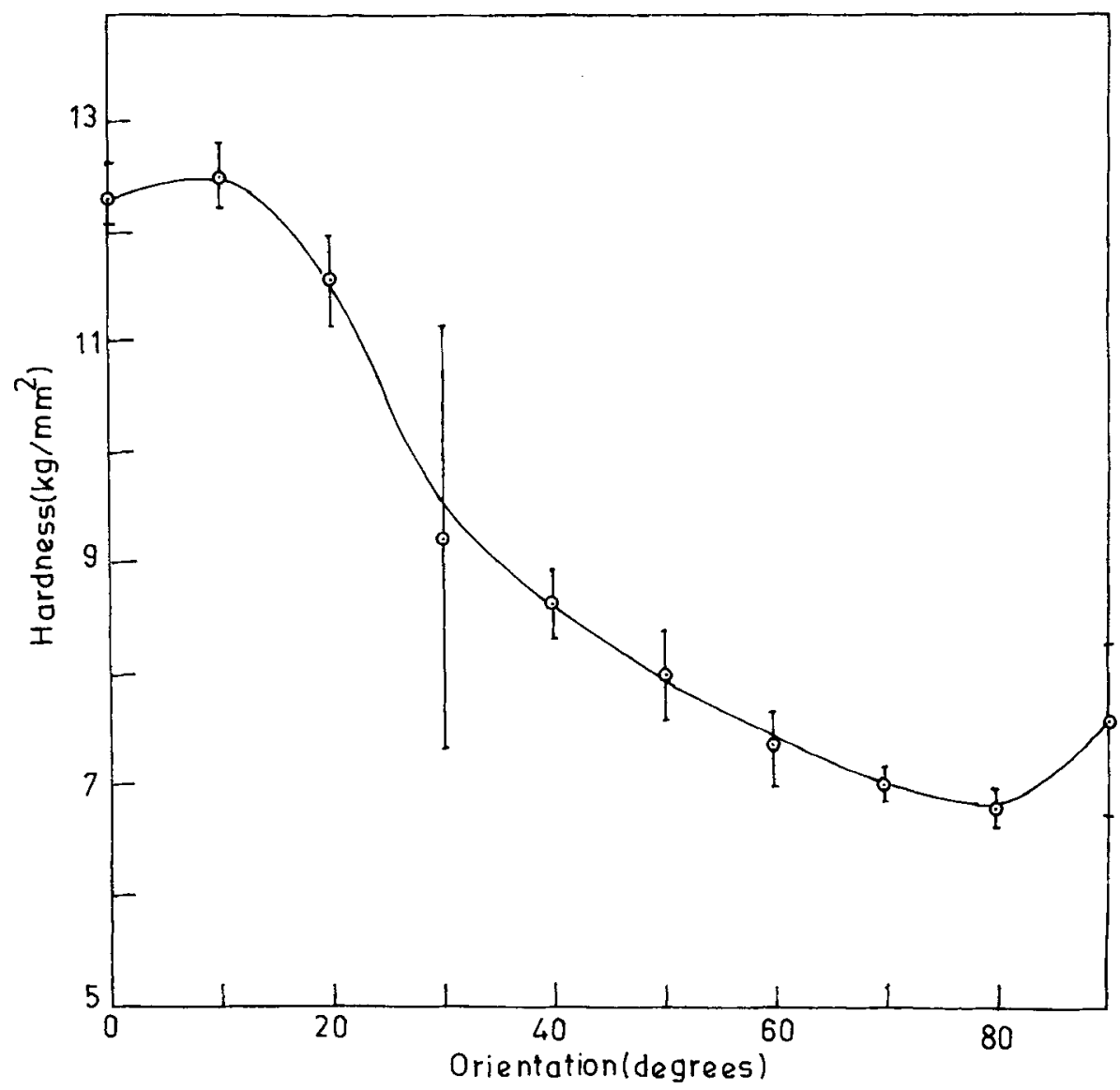

Figure 1. Variation of Knoop hardness with orientation on the (001) cleavage face of anthracene. 
long diagonal of the Knoop indenter is parallel to the [010] direction in the case of anthracene, whereas it is the least in the case of phenanthrene for the same orientation. The hardness values for the two cases is $12.3 \mathrm{~kg} / \mathrm{mm}^{2}$ and $8.8 \mathrm{~kg} / \mathrm{mm}^{2}$, respectively.

Tables 1 and 2 give the Knoop hardness data for anthracene and phenanthrene, respectively.

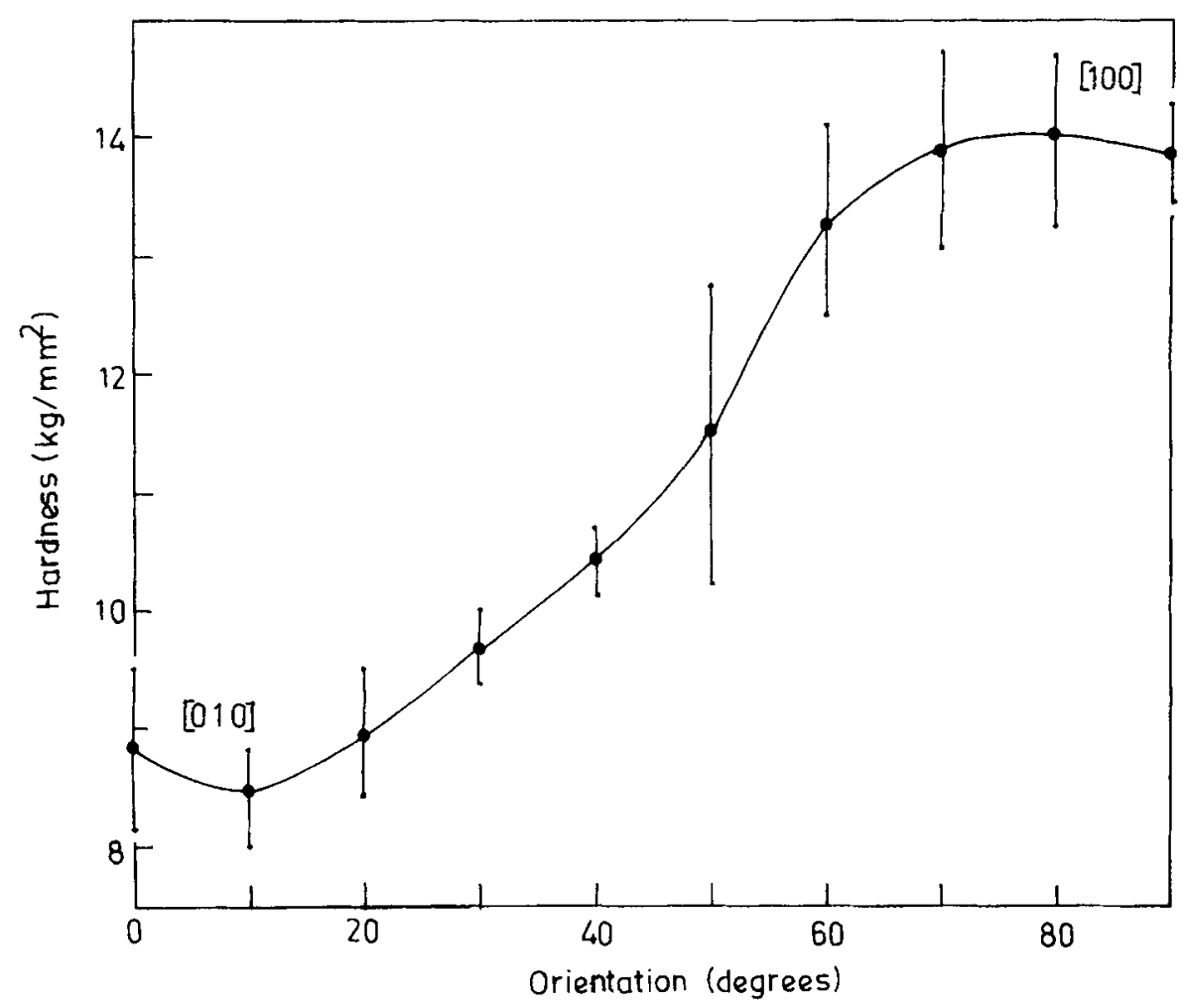

Figure 2. Variation of Knoop hardness with orientation on the (001) cleavage face of phenanthrene.

Table 1. Knoop hardness data for anthracene.

\begin{tabular}{lr}
\hline $\begin{array}{l}\text { Orientation } \\
\text { (degrees) }\end{array}$ & $\begin{array}{c}\text { Hardness } \\
\left(\mathrm{kg} / \mathrm{mm}^{2}\right)\end{array}$ \\
\hline 0 & $12 \cdot 32 \pm 0 \cdot 27$ \\
10 & $12 \cdot 50 \pm 0 \cdot 29$ \\
20 & $11 \cdot 60 \pm 0 \cdot 46$ \\
30 & $10 \cdot 18 \pm 1 \cdot 89$ \\
40 & $8 \cdot 72 \pm 0 \cdot 30$ \\
50 & $8 \cdot 05 \pm 0 \cdot 38$ \\
60 & $7 \cdot 23 \pm 0 \cdot 34$ \\
70 & $7 \cdot 08 \pm 0 \cdot 16$ \\
80 & $6 \cdot 85 \pm 0 \cdot 13$ \\
90 & $7 \cdot 65 \pm 0 \cdot 77$ \\
\hline
\end{tabular}


Table 2. Knoop hardness data for phenanthrene.

\begin{tabular}{lr}
\hline $\begin{array}{l}\text { Orientation } \\
\text { (degrees) }\end{array}$ & $\begin{array}{c}\text { Hardness } \\
\left(\mathrm{kg} / \mathrm{mm}^{2}\right)\end{array}$ \\
\hline 0 & $8 \cdot 83 \pm 0 \cdot 68$ \\
10 & $8 \cdot 45 \pm 0 \cdot 41$ \\
20 & $8 \cdot 97 \pm 0 \cdot 53$ \\
30 & $9 \cdot 68 \pm 0 \cdot 29$ \\
40 & $10 \cdot 44 \pm 0 \cdot 27$ \\
50 & $11 \cdot 50 \pm 1 \cdot 25$ \\
60 & $13 \cdot 28 \pm 0 \cdot 80$ \\
70 & $13 \cdot 90 \pm 0 \cdot 85$ \\
80 & $13 \cdot 97 \pm 0 \cdot 74$ \\
90 & $13 \cdot 85 \pm 0 \cdot 41$ \\
\hline
\end{tabular}

\section{Discussion}

Molecular solids encompass the largest group of solid materials because of vast varieties of organic molecular compounds. However, comparatively very less work has been reported on the microhardness studies of organic crystals. Vickers microhardness on $\{100\},\{001\}$ and $\{110\}$ forms of sucrose crystals has been studied and it was found that it correlates with the attachment energy rather than the surface energy (Sgualdino et al 1990). Also, there is a report on the study of Vickers hardness on sucrose single crystals (Elban et al 1994). The microhardness behaviour of quite a few organic molecular solids using pyramidal indenter have been reported (Joshi and Shah 1984; Marwaha and Shah 1991, 1992, 1996).

Anthracene and phenanthrene crystallize in the monoclinic structure. The lattice parameters for anthracene are $a=8.562 \AA, b=6.038 \AA$ and $c=11 \cdot 184 \AA$ with $B=124^{\circ} 7^{\prime}$ and for phenanthrene are $a=8.660 \AA, b=11.500 \AA$ and $c=19.240 \AA$ with $B=98^{\circ} 4^{\prime}$. Both these compounds have the same structural formula $\left(\mathrm{C}_{14} \mathrm{H}_{10}\right)$ with two molecules per unit cell but the molecules have different shapes. They have the same space group $P 2_{1 / a}$ and cleave along the (001) plane (Wyckoff 1951).

The hardness depends on the plastic and elastic properties of the crystals. For anisotropic materials, the properties vary with crystallographic orientations. In the case of Knoop indentations, the elastic recovery takes place along the short diagonal only and the long diagonal does not change when the load is removed. When a loaded indenter penetrates a solid, the depth of penetration increases until the condition of the lattice immediately below the indenter has the same characteristics as that of the specimen in which the saturation value of the compressive strain has been attained. The strain becomes progressively smaller with increasing distance from the centre of the material to a distance equal to the length of the long diagonal.

The microhardness properties are related to the crystal structure of the material or the way the atoms or molecules are packed together.

On indenting the (001) cleavage planes with the long axis of the Knoop indenter parallel to the [010] direction, slip lines are observed along this direction in the case of phenanthrene (Narang et al 1974), but not in the case of anthracene.

Figure 3 is a photomicrograph showing slip lines in phenanthrene around a Knoop indentation. 


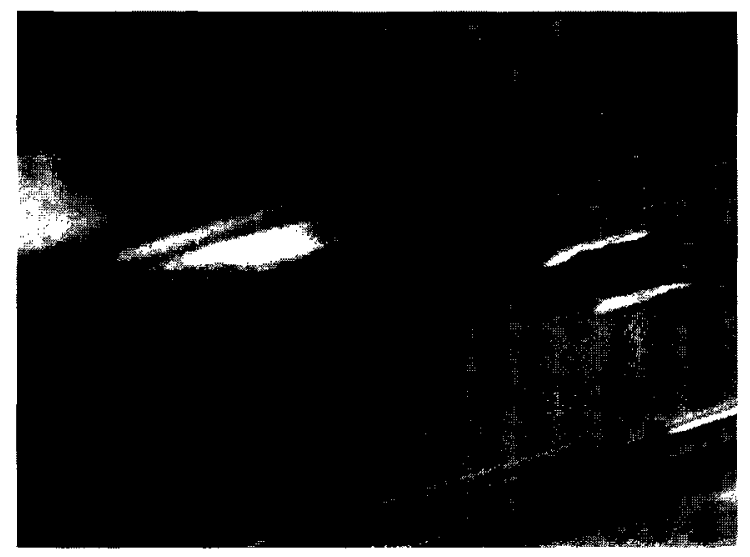

Figure 3. Photomicrograph showing slip lines in phenanthrene around a Knoop indentation.

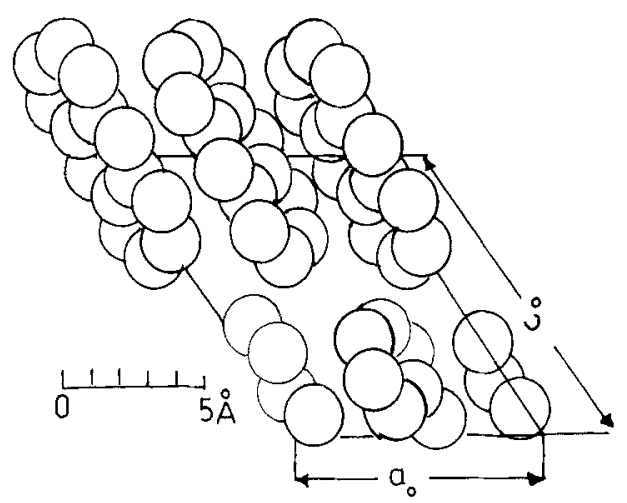

Figure 4. Arrangement of anthracene molecules on the ac face in the unit cell.

This causes the hardness value to be lower in the case of phenanthrene than anthracene. As the crystal is rotated in steps of $10^{\prime \prime}$ with respect to the long diagonal of the Knoop indenter, the microhardness values of anthracene decrease whereas those of phenanthrene increase till the long diagonal of the indentation mark is perpendicular to the $[010]$ direction or in the [100] direction.

Pyramidal microhardness investigations of the hardness variation with load (Marwaha and Shah 1991) show that the hardness value of phenanthrene is lower than that of anthracene in the lower load range, which supports the above observations.

Figures 4 and 5 show the arrangement of anthracene and phenanthrene molecules in the ac plane respectively. It is seen that the slip in the b-direction is easier in phenanthrene than anthracene. Thus the opposite behaviours of the microhardness variation with orientations are due to the way the molecules are oriented and packed in the respective unit cells.

\section{Conclusions}

The opposite nature of the microhardness variation with the crystal orientation in phenanthrene and anthracene is due to the orientation and disposition of molecules in 


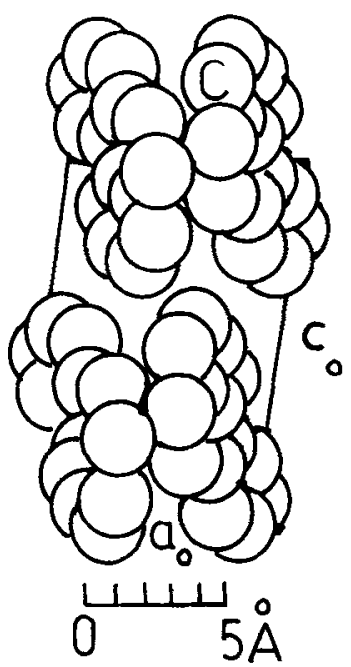

Figure 5. Arrangement of phenanthrene molecules on the ac face in the unit cell.

the respective unit cell, though they have the same molecular formula and crystal structure.

\section{Acknowledgements}

The authors thank Prof. J N Sherwood, University of Strathclyde, Glasgow, UK, for the generous supply of organic crystals, and Prof. V N Potbhare, M. S. University of Baroda, Vadodara, for facilities.

\section{References}

Elban W L, Sheen D B and Sherwood J N 1994 J. Cryst. Growth 137304

Fang Y, Danyluk S, Li Z and Lam D 1993 J. Mater. Sci. Lett. 121070

Han Y H, Hong Li, Wong T Y and Bradt R C $1991 \mathrm{~J}$. Am. Ceram. Soc. 743129

Joshi M J and Shah B S 1984 Cryst. Res. \& Technol. 191107

Marwaha R K and Shah B S 1991 Cryst. Res. \& Technol. 26491

Marwaha R K and Shah B S 1992 Cryst. Res. \& Technol. 271097

Marwaha R K and Shah B S 1996 Indian J. Pure \& Appl. Phys. 34550

Miller J C 1989 A study of mechanical deformation in single crystals of pentaerythritol tetranitrate and cyclotrimethylene trinitramine, Ph. D. Thesis, University of Strathclyde, Glasgow, UK

Mott B W 1956 Micro-indentation hardness testing (London: Butterworths)

Narang R S, Shah B S and Sherwood J N 1974 J. Cryst. Growth 22201

Sgualdino G, Vaccari G and Mantovani G 1990 J. Cryst. Growth 104527

Sherwood J N 1969 Fractional crystallization (ed.) M Zief (New York: Dekker) Vol. 2, p. 175

Thirmal Rao T, Krishna Rao K and Sirdeshmukh D B 1991 Cryst. Res. Technol. 26 K 189

Vaidya N and Shah B S 1997 Indian J. Phys. A71 55

Vaidya N, Shah B S and Joshi D R 1996 Indian J. Phys. A70 641

Wong T Y and Bradt R C 1992 Mater. Chem. Phys. (Switzerland) 30261

Wyckoff R W G 1951 Crystal structures (Interscience) 